\title{
Interleukin-3 plays a vital role in hyperoxic acute lung injury in mice via mediating inflammation
}

\author{
Zhijian Huang ${ }^{1 \dagger}$, Wei Zhang ${ }^{2 \dagger}$, Jian Yang ${ }^{2}$, Feiyu Sun ${ }^{1}$ and Hongwei Zhou $^{3 *}$
}

\begin{abstract}
Background: Interleukin (IL)-3 amplifies inflammation. However, the effect of IL-3 in acute lung injury (ALI), an acute inflammatory disease, is unclear. The aim of this study was to test the hypothesis that IL-3 plays an important role in hyperoxia-induced ALI.

Methods: Hyperoxic ALI was induced in wild-type (WT) and IL-3 gene disrupted (IL-3 $3^{-/-}$) mice by exposure to 100\% $\mathrm{O}_{2}$ for $72 \mathrm{~h}$.

Results: Hyperoxia increased IL-3 levels in plasma and lung tissues in WT mice. Pulmonary inflammation and edema were detected by histological assay in WT mice exposed to $100 \% \mathrm{O}_{2}$ for $72 \mathrm{~h}$. However, the hyperoxia-induced lung histological changes were improved in $\mathrm{IL}-3^{-/-}$mice. The hyperoxia-induced elevation of neutrophils in bronchoalveolar lavage fluids and circulation were reduced in IL-3 $3^{-1-}$ mice. Meanwhile, the levels of tumor necrosis factor-a and IL-6 were suppressed in IL-3 $3^{-1-}$ mice compared with WT mice. Moreover, the hyperoxia-induced the activation of IKBa kinase (IKK) $\beta$, IKBa phosphorylation, and nuclear factor-KB translocation were inhibited in IL- $3^{-/}$mice compared with WT mice.
\end{abstract}

Conclusions: Our results suggest IL-3 is a potential therapeutic target for hyperoxia-induced ALI.

Keywords: Interleukin-3, Acute lung injury, Inflammation, Hyperoxia

\section{Background}

Acute respiratory distress syndrome (ARDS) remains a major challenge in intensive care medicine [1,2]. Acute lung injury (ALI) is a mild form of ARDS. Inflammation is thought to contribute to the pathogenesis of ALI/ARDS [1-5], as ALI/ARDS is characterized by increased vascular permeability, extravasation of plasma, and neutrophil infiltration in the lung [1-4]. Thus, it is rational to explore anti-inflammatory therapies for this disorder $[1,5,6]$. However, it is bewildering that the results from clinical trials of novel anti-inflammatory strategies for ALI/ARDS have been disappointingly negative $[1,2,4,7]$. These results reflect an incomplete understanding of ALI/ARDS pathogenesis. Therefore, the complicated cellular and

\footnotetext{
* Correspondence: 2545419172@qq.com

${ }^{\dagger}$ Zhijian Huang and Wei Zhang contributed equally to this work.

${ }^{3}$ Department of Intensive Care Unit, Xia'men Traditional Chinese Medicine Hospital affiliated to Beijing University of Traditional Chinese Medicine, No.1739 Xianyue Road, Xia'men 361009, Fujian, China

Full list of author information is available at the end of the article
}

molecular mechanisms contributing to the pathogenesis of ALI/ARDS needs to be further elucidated.

A recent study showed that interleukin (IL)-3 and its specific receptor $\alpha$ chain (IL-3R $\alpha$, also know as CD123) axis is responsible for cytokine storm during the pathogenesis of cecal ligation and puncture induced sepsis [8]. IL-3/ CD123 axis is suggested as a potential therapeutic target for sepsis [8]. However, the underlying mechanism has not been adequately defined. Excessive cytokine-mediated inflammation plays a fundamental role in the pathogenesis of ALI/ARDS [9, 10], one of the most feared complications of sepsis $[9,11]$. Nuclear factor (NF)- $\mathrm{kB}$ is known as a pivotal inducer of proinflammatory cytokines and highly activated in various inflammation-related diseases such as ALI $[10,12,13]$. A previous in vitro study reported IL-3 has potential effect on induction of IKB $\alpha$ kinase (IKK) $\beta$ activation [14]. IKK plays a key role on regulation of NF- $k B$ activation [15]. In the present study, we investigated the role of IL-3 in hyperoxia-induced ALI.

(c) The Author(s). 2018 Open Access This article is distributed under the terms of the Creative Commons Attribution 4.0 International License (http://creativecommons.org/licenses/by/4.0/), which permits unrestricted use, distribution, and 
Our findings may suggest new therapeutic target to prevent the onset of hyperoxic lung injury.

\section{Methods}

\section{Animals}

All animal experiments were performed in accordance with the National Institutes of Health guidelines for the use of experimental animals. All animal care and experimental procedures used in the present study were approved by the Ethics committee of Beijing University of Traditional Chinese Medicine. Healthy wild-type (WT) C57BL/6 mice (6-8 weeks old, body weight $16-20 \mathrm{~g}$ ) were obtained from Beijing University of Traditional Chinese Medicine. IL-3 gene disrupted (IL- $3^{-/-}$) mice on a C57BL/6 background were obtained from The Jackson Laboratory (Bar Harbor, ME). All of our current studies were performed using male mice. The animals were housed in individually ventilated cages under a $12 \mathrm{~h}$ light/dark cycle. Before the experiment, mice were habituated to the environment for at least 1 week. Standard chow and water were provided ad libitum. All procedures were performed as humanely as possible to minimize animal suffering.

\section{Experimental protocol}

Mice were assigned to four groups $(n=8)$ : sham+WT mice, sham $+\mathrm{IL}-3^{-/}$mice, hyperoxia $+\mathrm{WT}$ mice, and hyperoxia+IL- $3^{-1-}$ mice. In brief, the mice were exposed to $100 \% \mathrm{O}_{2}$ in a specially constructed plexiglas chamber to induce hyperoxic ALI [16]. Mice in sham group were exposed in room air. Seventy-two hours after hyperoxia or room air challenge, mice were sacrificed after anesthesia by pentobarbitone $(50 \mathrm{mg} / \mathrm{kg}$ intraperitoneal injection) and were exsanguinated through the vena cava. Then, lung tissue sampling (for lung histology, and lung wet to dry weight ratio) was collected. Bronchoalveolar lavage fluids (BALF) and pulmonary tissue samples (for preparation of lung tissue homogenates) were collected in separate experiments.

\section{Lung histology}

The lungs were fixed with formalin overnight. Five micrometer sections were deparaffinized. The sections were stained by haematoxylin/eosin (H\&E). Lung injury scores were performed according to the following histological features: pulmonary edema, neutrophil infiltration, hyperemia, hemorrhage, and cellular hyperplasia. A score of 0 represented absent damage; 1 represented mild damage; 2 represented moderate damage; 3 represented severe damage [17].

\section{Lung water content}

To quantify the magnitude of pulmonary edema, we evaluated the dry to wet $(\mathrm{D} / \mathrm{W})$ ratio of the lung. The left main bronchi were clamped, and the wet left lung was harvested. They were then placed in an oven for $48 \mathrm{~h}$ at $80^{\circ} \mathrm{C}$. Lung water content was calculated as $(1-\mathrm{D} / \mathrm{W}) \times 100 \%$.

\section{Collection of BALF}

The trachea was cannulated, and the lung was lavaged with $0.5 \mathrm{~mL}$ PBS for six times. The recovery rate of BALF was $>90 \%$ in all samples. Collected BALF was centrifuged at 1,200 rpm for $3 \mathrm{~min}$. The supernatant was collected for further study.

\section{Enzyme linked immunosorbent assay (ELISA)}

The concentrations of tumor necrosis factor (TNF)- $\alpha$, IL-6, and IL-3 were measured by ELISA according to the manufacturer's instructions (R\&D Systems Inc., Minneapolis, MN, USA). The DNA-binding activity of NF- $k B$ p65 was determined using an ELISA NF- $\mathrm{kB}$ p65 transcription factor assay kit according to the manufacturer's instructions (Chemicon, Temecula, CA, USA).

\section{Western blotting analysis}

Cytoplasmic and nuclear proteins were extracted from frozen lung tissue with the Nuclear/Cytosol Extraction kit (BioVision, Inc., Mountain View, CA, USA) according to the manufacturer's instructions. Protein concentrations were determined using the bicinchoninic acid protein assay (Pierce, Rockford, IL, USA). $50 \mu \mathrm{g}$ of total protein were subjected to SDS-PAGE and transferred onto PVDF membranes. Membranes were blocked with $5 \%$ non-fat milk at room temperature for $3 \mathrm{~h}$, incubated with primary antibodies (Anti-NF- $\mathrm{kB}$ p65 (sc-7151) and

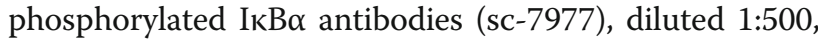
Santa Cruz Biotechnology, Santa Cruz, CA, USA; Anti-phosphorylated IKK $\alpha / \mathrm{IKK} \beta$ antibody (2078), diluted 1:500, Cell Signaling, Boston, MA, USA; Anti-IL-3 antibody (AF-403-NA), diluted 1:200, R\&D Systems Inc., Minneapolis, MN, USA; Anti-CD123 antibody (106002), diluted 1:200, Biolegend, San Diego, CA, USA) at $4{ }^{\circ} \mathrm{C}$ overnight. $\beta$-actin (3700) and Lamin B (12586) (Cell Signaling, Boston, MA, USA) were used as an internal control for cytoplasmic and nuclear protein, respectively. On the next day, membranes were incubated with HRP-conjugated secondary antibodies (Cell Signaling, Boston, MA, USA) at $37{ }^{\circ} \mathrm{C}$ for $1 \mathrm{~h}$. Protein bands on the membrane were visualized with ECL Kit (Biovision, Milpitas, CA, USA) using FluorChem FC3 system (ProteinSimple, San Jose, CA, USA). Results were presented as densitometric ratio between the protein of interest and the loading control.

\section{Survival study}

The survival rate was observed at 24-h intervals. Observation was continued $72 \mathrm{~h}$. 


\section{Statistical analysis}

All data were analyzed with GraphPad Prism 6.0 (GraphPad Software, CA, USA) and were presented as mean \pm SEM. Two-way ANOVA with Bonferroni's multiple-comparisons test was used for multiple group analysis. Histopathologic scores were compared using the Mann-Whitney $U$ test. The survival rate was estimated by the Kaplan-Meier method and compared by log-rank test. $P<0.05$ was accepted as statistically significant.

\section{Results}

\section{Effect of hyperoxia on IL-3 and IL-3Ra}

The levels of IL-3 and IL-3R $\alpha$ in the lung were detected by Western Blotting in additional groups of animals (Fig. 1a and Additional file 1: Figure S1). Hyperoxia caused significant increase of IL-3 in the lung (Fig. 1a). It was simultaneously associated with an increase in expression of IL-3R $\alpha$ in the lung $72 \mathrm{~h}$ after hyperoxia challenge (Fig. 1a). Moreover, the concentration of IL-3 in plasma was significantly elevated in hyperoxia exposure group compared with sham (Fig. 1a).

\section{Effects of IL-3 on lung injury and mortality in hyperoxia-} induced ALI

Hyperoxia caused significant neutrophil infiltration, alveolar capillary protein leak, and lung edema after $72 \mathrm{~h}$, which could be dampened in IL- $3^{-/-}$mice (Fig. 1b, c, d, and e). When IL- $3^{-/-}$mice were treated with hyperoxia, the lung histological changes were reduced compared with WT mice (Fig.1f; Fig. 2). All mice died within 3 days in hyperoxia+WT group. In contrast, mice were more resistant to hyperoxia in IL- $3^{-1-}$ mice. A total of $50 \%$ of the mice in the WT mice treated hyperoxia group died within $24 \mathrm{~h}$, and an additional $50 \%$ died within $72 \mathrm{~h}$, while $60 \%$ of the mice in the IL-3 ${ }^{-/-}$mice treated hyperoxia group survived.

\section{Effects of IL-3 on proinflammatory mediators in hyperoxia-induced ALI}

As proinflammatory cytokines have a key role in ALI $[10,12]$, the IL- 6 and TNF- $\alpha$ in BALF were studied in our study. Seventy-two hours after hyperoxia challenge, there was a significant reduction in TNF- $\alpha$ and IL- 6 concentrations in IL- $3^{-/-}$mice versus WT mice (Fig. 3a).

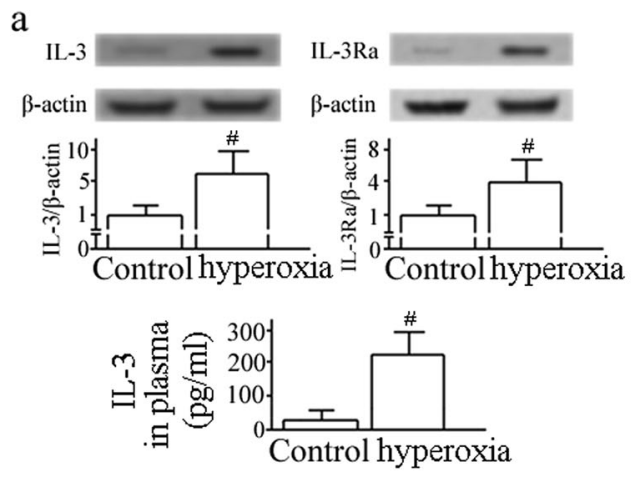

b

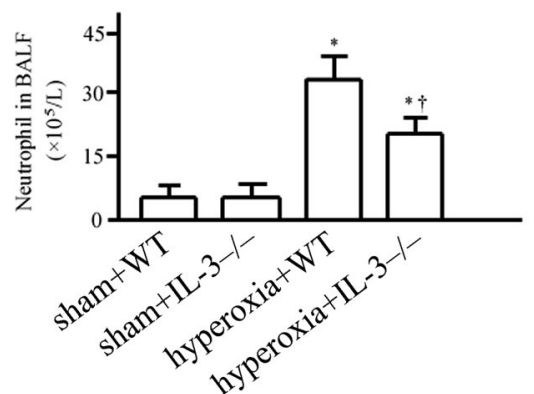

c

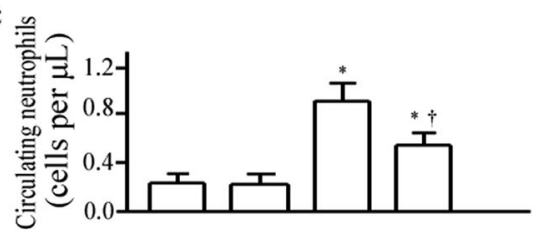

$\mathrm{d}$

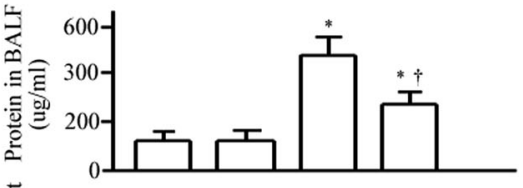

e

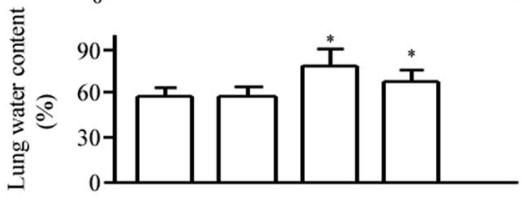

f

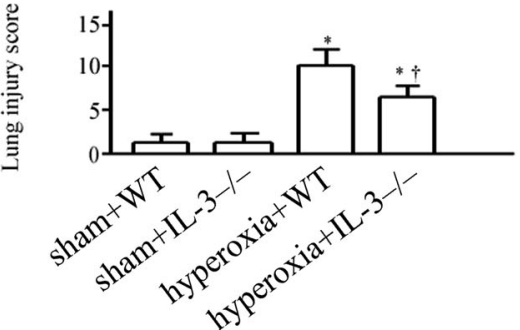

Fig. 1 Effect of hyperoxia on interleukin (IL)-3 and IL-3-specific receptor a chain (IL-3Ra). C57BL/6 mice were challenged with room air (control) or hyperoxia for $72 \mathrm{~h}$ and pulmonary protein of IL-3 and IL-3Ra were assessed by western blotting, and IL-3 levels in plasma was measured by enzyme linked immunosorbent assay (ELISA) (a). Neutrophils in bronchoalveolar lavage fluids (BALF) (b) and circulation (c), protein in BALF (d), lung edema (e), and lung injury score (f) were assessed $72 \mathrm{~h}$ after hyperoxia or room air challenge. Data represent assessments in a minimum of $n=5$ mice. ${ }^{\#} P<0.05$ vs. control; ${ }^{*} P<0.05$ vs. sham+wild type (WT) group; ${ }^{\dagger} P<0.05$ vs. hyperoxia $+W T$ group. IL- $3^{-/-}$, IL-3 gene disrupted mice 


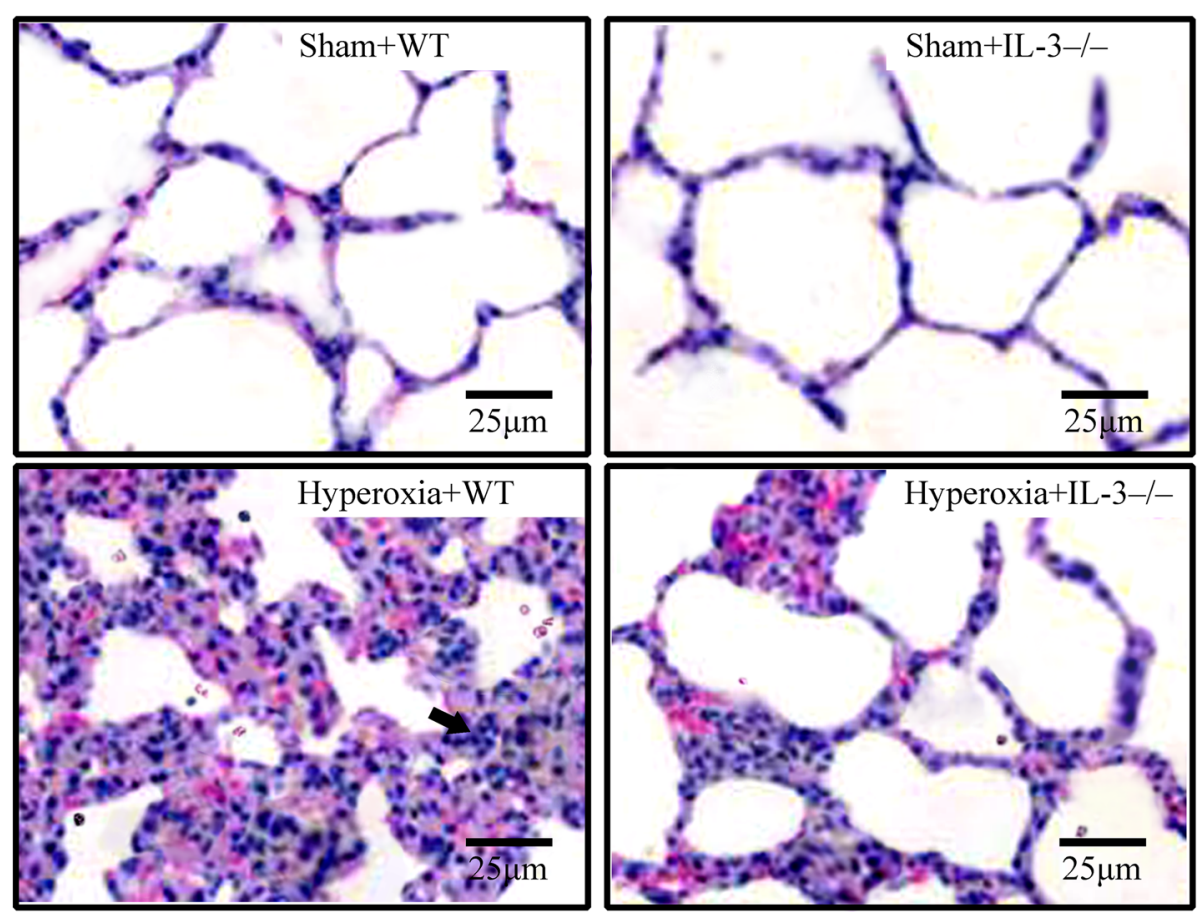

Fig. 2 Lung histological features were assessed $72 \mathrm{~h}$ after hyperoxia or room air challenge by light microscopy, hematoxylin and eosin stain in wild-type mice (WT) and interleukin-3 gene disrupted mice $\left(\mathrm{IL}-3^{-/-}\right)$. Original magnification, $\times 400$

\section{Effects of IL-3 on IKK/NF-KB pathway}

Hyperoxia exposure induced $I \kappa B$ phosphorylation and NF- $\mathrm{B}$ p 65 nuclear translocation in the lung (Fig. 3b, and c). NF- $\mathrm{B}$ p 65 levels in the nucleus and phosphorylated $\mathrm{I} \kappa \mathrm{B} \alpha$ levels in the cytoplasm were reduced in $\mathrm{IL}-3^{-/-}$mice (Fig. 3b, and $\mathrm{c}$ ). The hyperoxia-induced IKK $\beta$ activation was dampened in IL- $3^{-1-}$ mice (Fig. $3 \mathrm{~d}$ ). Hyperoxia exposure induced activation of $\mathrm{NF}-\mathrm{kB}$ was reduced in $\mathrm{IL}-3^{-/-}$mice (Fig. 3e).

\section{Discussion}

IL-3 was first reported to be a potential new therapeutic target for sepsis in 2015 [8]. However, the effect of IL-3 in ALI has been generally understudied. Our results showed that IL-3 gene deleted mice have improved lung inflammation and edema in hyperoxia-induced ALI. Moreover, hyperoxia-induced the activation of IKK/ NF- $\mathrm{kB}$ signaling pathways and upregulation of proinflammatory mediators were reduced in $\mathrm{IL}-3^{-/-}$mice.

Lines of evidence have shown that IL-3 is released by activated Th2 lymphocytes which play crucial roles in allergic disorders $[8,18]$. IL-3 is also known as multi-potential colony-stimulating factor which stimulating proliferation of pluripotent hematopoietic stem cells and progenitor cells [19-21]. A recent study suggests that IL-3 plays a vital role in sepsis [8], an infectious disorder [9, 11]. IL-3 plays its effect via combining with its receptor. The IL-3 receptor is a heterodimer which composed of one $\alpha$ chain and one $\beta$ chain $[19,22]$. The $\alpha$ chain is IL-3 specific receptor also known as CD123. IL-3R $\alpha$ is expressed in hematopoietic stem and progenitor cells, dendritic progenitors, and macrophage $[8,19]$. These cells were infiltrated in the lung in the pathogenesis of ALI. In the present study, a significant increase in IL-3 and IL-3R $\alpha$ levels in the lung homogenates $72 \mathrm{~h}$ after hyperoxia stimulation was detected by Western Blotting.

Over released proinflammatory mediators are crucial to the initiation of inflammatory tissue injury [9]. The influence of IL-3 and it receptor on proinflammatory mediators has been reported $[8,14,23,24]$. A previous in vitro study suggests a potential posttranscriptional regulation effect of IL-3 on TNF- $\alpha$ via a p38-mitogen-activated protein kinase and silent information regulator type-2-dependent manner [23]. The limiting role of anti-CD123 in cytokine secretion has been recognized previously [8]. Our data showed that TNF- $\alpha$ and IL- 6 were reduced in IL-3 gene deleted mice compared with WT mice at $72 \mathrm{~h}$ after hyperoxia stimulation. However, little is known regarding the underlying mechanisms. IKK/NF-kB pathway is one critical transcriptional mechanism required for maximal expression of many cytokines involved in the pathogenesis of ALI $[10,12]$. A previous in vitro study reported IL-3 induces the activation of IKK $\beta$ in mast cell via a Src family kinase and $\mathrm{Ca}^{2+}$ dependent manner [14]. Activation 


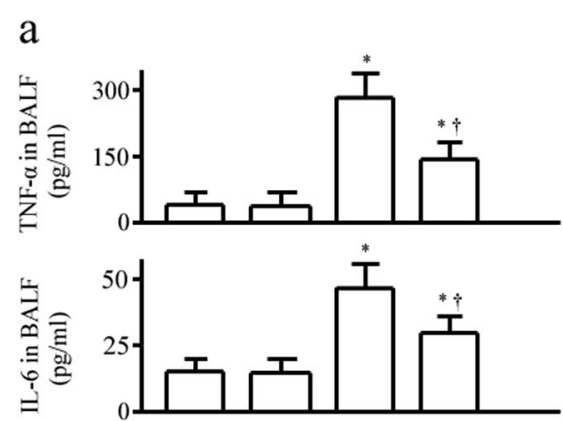

C
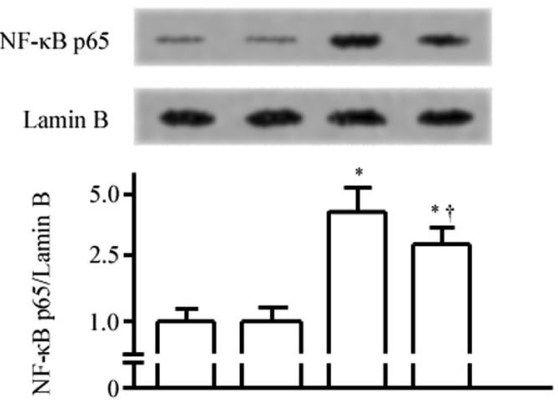

d

b
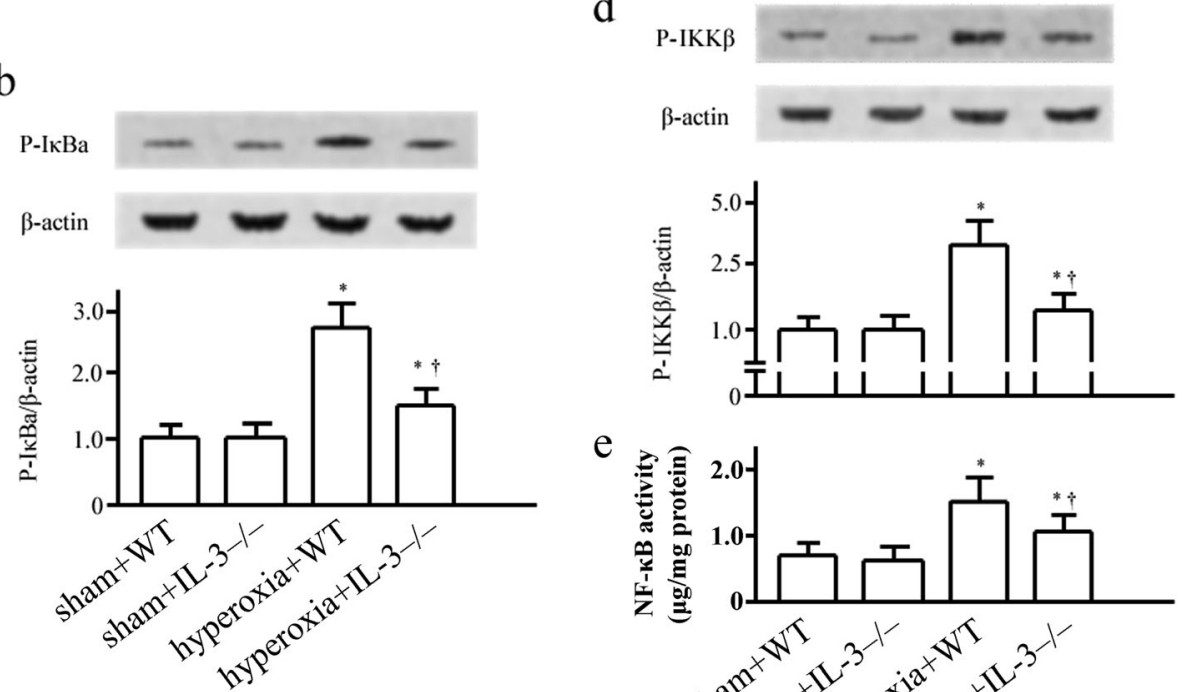

e

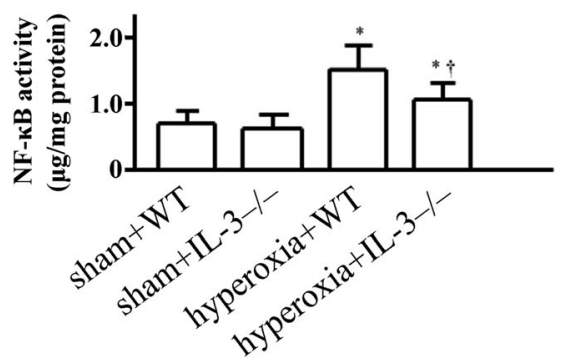

Fig. 3 Effect of IL-3 on proinflammatory mediators and nuclear factor (NF)-kB activation in mice. Tumor necrosis factor (TNF)-a and interleukin (IL)-6 (a) in bronchoalveolar lavage fluids (BALF), phosphorylated (p)-IKBa in the cytoplasm (b), nuclear factor (NF)-KB p65 in the nucleus (c), p-IKBa kinase (IKK) $\beta$ (d), and NF-KB activity (e) in lung tissues were assessed 72 hours after hyperoxia or room air challenge by enzyme linked immunosorbent assay (ELISA) or western blotting. Data represent assessments in a minimum of $\mathrm{n}=5$ mice. ${ }^{*} P<0.05$ vs. sham+wild type (WT) group; $+P<0.05$ vs. hyperoxia+WT group. IL-3-/-, IL-3 gene disrupted mice

of IKK induces phosphorylation and degradation of IкB, leading to the nuclear translocation of NF- $\mathrm{kB}$ and transcriptional activation [15]. Our results showed that the IL-3 levels in the lung and plasma were significantly elevated in hyperoxia exposure group compared with sham. Meanwhile, the IKK/NF- $\mathrm{BB}$ pathway was activated by hyperoxia exposure. However, when the IL-3 gene was deleted in mice, the hyperoxia-induced the activation of IKK/NF- $\mathrm{kB}$ pathway and cytokine productions were dampened. Our results suggest that IL-3 is associated with the activation of IKK/NF- $\mathrm{KB}$ pathway. However, the precise mechanism responsible for the effect of IL-3 on the IKK/NF- $\mathrm{kB}$ pathway and cytokine productions warrants further investigation.

Overall, our data suggest that IL-3 and its receptor IL-3R $\alpha$ are induced during hyperoxia-induced lung injury, and thus further mediate inflammation via IKK/ $\mathrm{NF}-\mathrm{kB}$ axis to promote proinflammatory cytokine production and elevate inflammation.

\section{Conclusions}

In summary, our findings show that IL-3 and IL-3R $\alpha$ are stimulated in mice hyperoxia-induced ALI. Deletion of IL-3 reduced hyperoxia-induced ALI. Our results suggest IL-3 is a potential therapeutic target for hyperoxia-induced ALI.

\section{Additional file}

Additional file 1: Figure S1. Expression of interleukin (IL)-3 in the lung in wild-type (WT) and IL-3 gene disrupted (IL-3-- $3^{--}$mice was detected by western blot. (TIF $583 \mathrm{~kb}$ )

\section{Abbreviations}

ALl: Acute lung injury; ANOVA: Analysis of variance; ARDS: Acute respiratory distress syndrome; BALF: Bronchoalveolar lavage fluid; ELISA: Enzyme-linked immunosorbent assay; IKK: IKBa kinase; IL-3: Interleukin-3; IL-3Ra: Interleukin-3 specific receptor a chain; ROS: Reactive oxygen species; TNF-a: Tumor necrosis factor; W/D: Lung wet/dry weight ratio; WT: Wild-type 


\section{Acknowledgments}

We thank M.Y. Xiao and X. Chen for help with the lung histology evaluation. We thank M. Luo, Ph. D, C. Zhu and J. Lu for their help with the experiment. All authors have read and approved the manuscript.

\section{Availability of data and materials}

The datasets used and/or analyzed during the current study available from the corresponding author on reasonable request.

\section{Authors' contributions}

ZJH, WZ and HWZ had full access to all of the data in the study and take responsibility for the integrity of the data and the accuracy of the data analysis. JY and FYS contributed to the coordination of the study and review of the manuscript. All authors read and approved the final manuscript.

\section{Ethics approval and consent to participate}

All animal experiments were performed in accordance with the National Institutes of Health quidelines for the use of experimental animals. All animal care and experimental procedures used in the present study were approved by Beijing University of Traditional Chinese Medicine.

\section{Consent for publication}

Not applicable.

\section{Competing interests}

The authors declare that they have no competing interests.

\section{Publisher's Note}

Springer Nature remains neutral with regard to jurisdictional claims in published maps and institutional affiliations.

\section{Author details}

'Department of Emergency, Xia'men Traditional Chinese Medicine Hospital affiliated to Beijing University of Traditional Chinese Medicine, Xia'men, Fujian, China. ${ }^{2}$ Department of Respiratory, Jiangning Hospital affiliated to Nanjing Medical University, Nanjing, Jiangsu, China. ${ }^{3}$ Department of Intensive Care Unit, Xia'men Traditional Chinese Medicine Hospital affiliated to Beijing University of Traditional Chinese Medicine, No.1739 Xianyue Road, Xia'men 361009, Fujian, China.

Received: 12 May 2018 Accepted: 18 September 2018

Published online: 30 October 2018

\section{References}

1. Sweeney RM, McAuley DF. Acute respiratory distress syndrome. Lancet. 2016;388(10058):2416-30

2. Leaver SK, Evans TW. Acute respiratory distress syndrome. Bmj. 2007; 335(7616):389-94.

3. Aschner Y, Zemans RL, Yamashita CM, Downey GP. Matrix metalloproteinases and protein tyrosine kinases: potential novel targets in acute lung injury and ARDS. Chest. 2014;146(4):1081-91.

4. Matthay MA, Idell S. Update on acute lung injury and critical care medicine 2009. Am J Respir Crit Care Med. 2010;181(10):1027-32.

5. Tao W, Li PS, Xu G, Luo Y, Shu YS, Tao YZ, Yang LQ. Soluble Epoxide Hydrolase Plays a Vital role In Angiotensin II-Induced Lung Injury in Mice. Shock (Augusta, Ga). 2017.

6. Tao W, Li PS, Yang LQ, Ma YB. Effects of a soluble epoxide hydrolase inhibitor on lipopolysaccharide-induced acute lung injury in mice. PLoS One. 2016;11(8):e0160359.

7. Wheeler AP, Bernard GR. Acute lung injury and the acute respiratory distress syndrome: a clinical review. Lancet. 2007;369(9572):1553-64.

8. Weber GF, Chousterman BG, He S, Fenn AM, Nairz M, Anzai A, Brenner T, Uhle F, Iwamoto Y, Robbins CS, et al. Interleukin-3 amplifies acute inflammation and is a potential therapeutic target in sepsis. Science. 2015; 347(6227):1260-5

9. Gotts JE, Matthay MA. Sepsis: pathophysiology and clinical management BMJ. 2016:353:11585

10. Meduri GU, Annane D, Chrousos GP, Marik PE, Sinclair SE. Activation and regulation of systemic inflammation in ARDS: rationale for prolonged glucocorticoid therapy. Chest. 2009;136(6):1631-43.
11. Tao W, Li PS, Shen Z, Shu YS, Liu S. Effects of omega-3 fatty acid nutrition on mortality in septic patients: a meta-analysis of randomized controlled trials. BMC Anesthesiol. 2016;16(1):39.

12. Wright JG, Christman JW. The role of nuclear factor kappa B in the pathogenesis of pulmonary diseases: implications for therapy. Am J Respir Med. 2003;2(3):211-9.

13. Masterson C, O'Toole D, Leo A, McHale P, Horie S, Devaney J, Laffey JG. Effects and mechanisms by which Hypercapnic acidosis inhibits Sepsisinduced canonical nuclear factor-kappaB signaling in the lung. Crit Care Med. 2016:44(4):e207-17.

14. Drube S, Weber F, Loschinski R, Beyer M, Rothe M, Rabenhorst A, Gopfert C, Meininger I, Diamanti MA, Stegner D, et al. Subthreshold IKK activation modulates the effector functions of primary mast cells and allows specific targeting of transformed mast cells. Oncotarget. 2015;6(7):5354-68.

15. Hinz M, Scheidereit C. The IkappaB kinase complex in NF-kappaB regulation and beyond. EMBO Rep. 2014;15(1):46-61.

16. Tao W, Shu YS, Miao QB, Zhu YB. Attenuation of hyperoxia-induced lung injury in rats by adrenomedullin. Inflammation. 2012;35(1):150-7.

17. Bachofen $M$, Weibel ER. Structural alterations of lung parenchyma in the adult respiratory distress syndrome. Clin Chest Med. 1982;3(1):35-56.

18. Schroeder JT, Chichester KL, Bieneman AP. Human basophils secrete IL-3: evidence of autocrine priming for phenotypic and functional responses in allergic disease. J Immunol. 2009;182(4):2432-8.

19. Hara T, Miyajima A. Function and signal transduction mediated by the interleukin 3 receptor system in hematopoiesis. Stem Cells. 1996;14(6):605-18.

20. Hapel AJ, Fung MC, Johnson RM, Young IG, Johnson G, Metcalf D. Biologic properties of molecularly cloned and expressed murine interleukin-3. Blood. 1985;65(6):1453-9.

21. Metcalf D, Begley CG, Johnson GR, Nicola NA, Lopez AF, Williamson DJ. Effects of purified bacterially synthesized murine multi-CSF (IL-3) on hematopoiesis in normal adult mice. Blood. 1986;68(1):46-57.

22. Williams GT, Smith CA, Spooncer E, Dexter TM, Taylor DR. Haemopoietic colony stimulating factors promote cell survival by suppressing apoptosis. Nature. 1990;343(6253):76-9.

23. Borriello F, lannone R, Di Somma S, Loffredo S, Scamardella E, Galdiero MR, Varricchi G, Granata F, Portella G, Marone G. GM-CSF and IL-3 modulate human monocyte TNF-alpha production and renewal in in vitro models of trained immunity. Front Immunol. 2016;7:680.

24. Singha AK, Bhattacharjee B, Saha B, Maiti D. IL-3 and GM-CSF modulate functions of splenic macrophages in ENU induced leukemia. Cytokine. 2017; 91:89-95.

Ready to submit your research? Choose BMC and benefit from

- fast, convenient online submission

- thorough peer review by experienced researchers in your field

- rapid publication on acceptance

- support for research data, including large and complex data types

- gold Open Access which fosters wider collaboration and increased citations

- maximum visibility for your research: over $100 \mathrm{M}$ website views per year

At $\mathrm{BMC}$, research is always in progress.

Learn more biomedcentral.com/submissions 